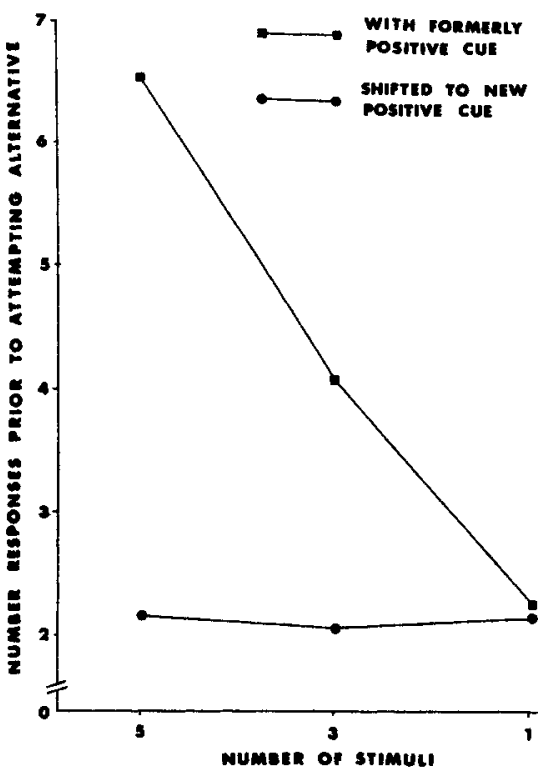

Fig. 1. Number of trials before attempting an alternative response as a function of number and location of stimuli.

stimulus location effect ( $F=6.50$, df $=1 / 66, p<.02)$ with attempts to try alternative responses being retarded when the stimuli remained with the formerly positive cue. Tests of the effects of number of stimuli and Number by Location interaction were not significant. The effect of number appears random when stimuli are shifted to the new positive cue. When, however, the stimuli remain with the formerly positive cue there is an apparent number effect.

The second analysis was conducted on the number of trials to achieve RS criterion in the test problems. These data are presented in Table 1 . A 3 by 2 analysis again indicated a significant $(F=5.95, \mathrm{df}=1 / 66, \mathrm{p}<.02)$ location effect revealing a negative relationship between RS speed and commonality of the reinforcement complex associated with the training and test problems. Results related to number of stimuli appear similar to those obtained for the data on number of responses prior to attempting an alternative. One exception, likely due to random variation, occurred with the apparently inflated mean of the group receiving one stimulus with the formerly positive cue.

Table 1

Means and SDs of Trials to Criterion for Groups Varying in Terms of Number and Location of Stimuli

\begin{tabular}{llrrrr}
\hline Location of & & \multicolumn{3}{c}{ Number of stimuli } \\
stimuli & & \multicolumn{2}{c}{5} & \multicolumn{1}{c}{3} & \multicolumn{1}{c}{1} \\
\hline With formeriy & M & 17.33 & 13.00 & 15.25 \\
positive cue & SD & 14.14 & 10.07 & 11.31 \\
Shifted to new & M & 8.83 & 7.58 & 10.17 \\
positive cue & SD & 7.50 & 8.04 & 10.82 \\
\hline
\end{tabular}

Variation in the reinforcement complex significantly alters RS performance possibly by increasing the probability of cue sampling in the test problem and reducing the number of perseverative errors. These results suggest that it might be interesting to examine the effect of stimulus variation factors which may relate to other aspects of the experimental situation. For example, in many studies, there is considerable stimulus variation associated with changes in the discriminanda utilized in training and test problems. Perhaps the greater the similarity between the discriminanda associated with both training and test problems, the slower the learning of the test problems. Such a prediction is important to studies which attempt to compare RS learning with nonreversal shift (NRS) learning. If, as is often the case, the discriminanda associated with both training and test tasks are more homogeneous for one kind of shift than another, then comparisons between shifts would be meaningful only in terms of stimulus variation factors. Variations in

\title{
Learning time with a mnemonic system
}

EDWARD BERLA, J. J. PERSENSKY, and R. J. SENTER, University of Cincinnati, Cincinnati, Ohio 45221

Subjects trained in the use of a commercial mnemonic technique ("hook" or "peg" system) and Ss trained by a traditional rote procedure were tested on the total time required to learn a list of 20 concrete nouns. Mnemonically trained Ss learned the list in significantly less time than did rote-control Ss. Results do not support the "total time" hypothesis.

According to Yates (1966) general mnemonic systems have existed since the golden age of Greece. Several modern authors of commercial texts (Furst, 1949, 1957; Lorayne, 1957; Roth, 1961) have claimed general utility for mnemonic techniques as aids to rote learning. $A$ basic part of all commercial mnemonic systems is a "hook" or "peg" system which consists of a highly overlearned list of common nouns memorized in a coded sequence. On subsequent learning of new lists, $S$ merely has to associate each new word with the appropriate word in the previously overleamed list. This association is typically accomplished by forming a "bizarre" mental discriminanda associated with training and test tasks in both RS and NRS problems are currently being investigated.

\section{REFERENCES}

FRITZ, B., \& BLANK, M. Role of the irrelevant cue in rapid reversal learning in nursery school children. Journal of Comparative \& Physiological Psychology, 1968, 65, 375-378.

HEAL, L. W., BRANSKY, M. L., \& MANKINEN, R. L. The role of dimension preference in reversal and nonreversal shifts of retardates. Psychonomic Science, 1966, 6, 509-510.

KENDLER, T. S., \& KENDLER, H. H. Reversal and nonreversal shifts in kindergarten children. Journal of Experimental Psychology, 1959, 58, 56-60.

SUTHERLAND, N. S. Stimulus analyzing mechanisms. In Proceedings of a symposium on the mechanization of thought processes. Vol. 2. London: Her Majesty's Stationery Office, 1959. YOUNISS, J., \& FURTH, H. G. Reversal learning in children as a function of overtraining and delayed transfer. Journal of Comparative \& Physiological Psychology, 1964, 57, 155-157. VINEY, W., HULICKA, I., BITNER, J., RALEY, C. L., \& BREWSTER, P. Effect of stimulus variation upon resistance to extinction in kindergarten children. Journal of Comparative \& Physiological Psychology, 1968, 65, 539-541. image involving both a previously overlearned word (called a "hook" or "peg") and the new word. During recall S retrieves the new word from memory by retrieving the "hook" or "peg" to which the new word is "attached." This retrieval of the "hook" is supposed to produce automatic retrieval of the newly associated word.

There has been little formal experimental investigation of mnemonic techniques. Wood (1967) conducted experiments in which Ss were presented a list of printed "hooks" to be used as mediators in the learning of a different list of common nouns. The results showed that Ss who were instructed how to use the "hook" words as mediators recalled significantly more words than Ss who were not so instructed or who did not have the printed "hooks."

Senter \& Hauser (1968) required Ss to remember mnemonic "hooks" rather than allowing visual access to the "hooks" in printed form. Ss who were trained in the use of mnemonics performed significantly better in the number of CVC items they could correctly anticipate as compared to untrained Ss using CVC items of the same association value.

These, and other studies (Persensky \& Senter, in press; Ross \& Lawrence, 1968), have suggested that the use of general 
mnemonic systems enhances the learning of verbal material to a level superior to that ordinarily accomplished through traditional rote procedures. All of these studies have used the number of items correctly recalled after a fixed number of trials as a criterion for "superiority." In all of these studies little or no attention has been paid to the amount of time required by Ss to learn their lists. Cooper \& Pantle (1967) have suggested a principle (the "total time hypothesis") which states that "a fixed amount of time is necessary to leam a fixed amount of material regardless of the number of individual trials into which that time is divided [p. 221]." Cooper \& Pantle (1967) have also suggested that a distinction be made between "nominal time" (the amount of clock time available for rehearsal) and "effective time" (the amount of nominal time during which rehearsal actually occurs). This implies that the fact that the control and experimental $S s$ in the previously cited mnemonic experiments had a controlled number of trials does not preclude the possibility that the mnemonic groups had more total practice.

If, on the other hand, the claims of the authors of commercial texts are correct, then: (1) a group of Ss trained in the use of mnemonics should be able to learn and subsequently recall more items in the same amount of time (or less) than could a nontrained learning control, or (2) take less time to learn the same list as compared to the rote learning control. Both these claims are in direct opposition to the total time hypothesis. It is the purpose of the present study to investigate the temporal aspects of the learning process in Ss using a mnemonic system.

\section{METHOD}

Fifty-six male and female Ss participated in the experiment as part of a course requirement at the University of Cincinnati. The Ss were randomly assigned to treatments. E group Ss were given a training session (approximately $30 \mathrm{~min}$ ) which consisted of two parts: (1) an explanation of a "hook" mnemonic system (Furst, 1949) and the memorization of 20 especially designed "hook" words, followed by (2) a practice session in which they learned a list of 20 words using the "hook" technique previously described to them. Control Ss were also given a training session in which they learned two lists of 20 words by traditional rote procedures. The first list consisted of the same 20 words used as "hooks" in the E groups and the second list was the same as that learned by the $E$ groups in practicing the mnemonic system.

After training the experimental Ss were randomly divided into two groups. One E group was provided with printed "hooks" on their answer sheets while the other $\mathrm{E}$ group did not have the "hooks" printed and therefore had to remember their mnemonic "hooks." Control Ss who were not instructed in mnemonics did not, of course, have the "hooks" printed on their answer sheets.

Immediately following the pretraining sessions both experimental and control Ss were given a third list of 20 words to memorize. The list of 20 words was printed in a booklet with only one word on a page. The Ss were instructed to memorize the list of 20 words in the order in which they were presented and also to keep track of the time spent in learning each word. In order for the Ss to keep track of their time, a Carousel slide projector flashed consecutive numbers on a screen every $5 \mathrm{sec}$. The $\mathrm{Ss}$ were instructed to write the number being projected on the screen next to the word they were memorizing before going on to the next word and also to write the number being projected on the screen when they completed recalling the entire list. If the Ss were unable to leam the list in one trial they were required to continue to review it until they were able to recall all the words in the correct order. The test list was composed of 20 concrete nouns from the ThorndikeLorge list (1944) with occurrences ranging from 2 per million to 100 per million.

\section{RESULTS}

Two separate analyses were performed on the data, namely: (1) the total time needed to learn the list of 20 words in their correct order with the time needed for writing their recall included, and (2) the total time required to learn the list minus the time needed for recall. Both the analyses yielded statistically significant $F$-ratios $[F=3.89$, $\mathrm{df}=2 / 55, \mathrm{p}<.05$ (including recall time); $\mathrm{F}=7.91, \quad \mathrm{df}=2 / 55, \quad \mathrm{p}<.01 \quad$ (excluding recall time)] . A Neuman-Keuls test (Winer, 1962) was employed to determine which mean differences were significant. The test showed that each mnemonic group required significantly less time to learn the list than did the control group $(p<.05)$. This test also showed that those E group Ss who did not have access to the printed "hooks" while learning the list required significantly less time $(\mathrm{p}<.05)$ than those $\mathrm{E}$ group Ss who had access to printed "hooks."

A chi-square analysis showed that there was no significant difference between $\mathrm{C}$ and $E$ groups in the number of trials necessary to learn the list $\left(\chi^{2}=3.28, \mathrm{df}=4\right)$.

$$
\text { DISCUSSION }
$$

The results of this study show that Ss who received mnemonic training learned a list of concrete nouns in significantly less time than did Ss who did not receive this training. These findings support and extend the findings of other researchers (Wood, 1967; Senter \& Hauser, 1968) indicating that mnemonically trained Ss show superior performance to Ss not receiving such training.
The results of the present study are not in accord with the logical dictates of the total time hypothesis. The results suggest that $\mathrm{Ss}$ who receive training in mnemonics were more efficient (in terms of time spent per item learned) than were Ss who did not receive such training.

Previous studies (Ross \& Lawrence, 1968 Senter \& Hauser, 1968) have either failed to use a proper control group and/or have not equated mnemonically trained Ss with untrained Ss in the amount of pretesting practice. The criticism can be made that because mnemonically trained Ss customarily receive practice sessions as part of their training, nonspecific or specific transfer effects could account for the mnemonic groups' superior performances. However, the use of a control group which had a pretesting practice session with lists identical to those used by the mnemonics groups in the present study, obviates this criticism.

An unexpected finding was that the Ss who were required to remember the "hooks" required significantly less time to learn the list than did the Ss who had access to printed "hooks." This suggests the possibility that the reading of the printed "hooks" contributes significantly to the total time necessary in learning the list or that Ss were checking to see if their previously memorized "hooks" were correct. Either of these operations would contribute to the total time necessary to learn the list. In any event, it would appear that the use of the memorized hooks provided a more efficient learning aid than did reference to a printed list of those hooks for Ss with the same training in the use of the mnemonic technique.

\section{REFERENCES}

COOPER, E. H., \& PANTLE, A. J. The total time hypothesis in verbal learning. Psy chological Bulletin, 1967, 68, 221-234.

FURST, B. Stop forgetting. New York: Greenburg, 1949.

FURST, B. The practical way to a better memory. New York: Fawcett World Library, 1957.

LORAYNE, H. How to develop a super-power memory. New York: F. Fell, 1957.

PERSENSKY, J. J., \& SENTER, R. J. An experimental investigation of a mnemonic system in recall. Psychological Record, in press.

ROSS, J., \& LAWRENCE, K. Some observations on memory artifice. Psychonomic Science, $1968,13,107-108$.

ROTH, D. M.Roth memory course. Santa Monica: Motivation, 1961.

SENTER, R. J., \& HAUSER, G. K. An experimental study of a mnemonic system. Psychonomic Science, 1968, 10, 289-290.

WINER, B. J. Statistical principles in experimental design. New York: McGraw-Hill, 1962.

WOOD, G. Mnemonic systems in recall. Journal of Educational Psychology Monograph, 1967, 58, 1-27.

YATES, F. A. The art of memory. London: Routledge \& Kegan Paul, 1966.

\section{NOTE}

1. This study represents a portion of the effort undertaken under Air Force Contract No. F33615-67-C-1469. 